\title{
Inherited Pericentric Inversion of a Human Y Chromosome in Trisomic Down's Syndrome ${ }^{\star}$
}

\author{
R. S. SPARKES, H. M. MULLER, and I. C. VEOMETT
}

From the Departments of Medicine and Pediatrics, UCLA School of Medicine, Los Angeles, California 90024, U.S.A.

Chromosomal inversions appear to be common in many organisms, but their frequency in humans is not known. Routine human mitotic chromosome studies have shown few pericentric inversions, and meiotic studies, which can reveal pericentric and paracentric inversions, have been less extensively applied to human chromosomes. The evaluation of possible chromosomal inversions has also been limited by not being able to localize the few human linkage groups to specific chromosomes other than to the $\mathrm{X}$ chromosome.

We here report studies of a Down's syndrome patient and his family in which an inherited pericentric inversion of the $\mathrm{Y}$ chromosome occurs.

\section{Case Report}

The patient was first admitted to UCLA Medical Center at 18 days of age for evaluation of suspected Down's syndrome. He was the product of a full-term pregnancy of a gravida 2, para 2 mother who was 24

Received 29 September 1969.

* Supported in part by Grant No. MR 0504A68 from the Division of Mental Retardation, SRS, HEW, and by California State Department of Mental Hygiene Grant DMH 62-14-9.8. years old. The father was 33 years old and there was a 2-year-old normal sister. The mother, father, and sister are all phenotypically normal. There was no positive family history for other instances of Down's syndrome, mental retardation, or other congenital abnormalities. The father is one of identical twins, based upon similarity in appearances and identity in the following: 13 red cell antigens; one Inv and four Gm types; haptoglobin types; and erythrocyte phosphoglucomutase electrophoretic types. The pedigree shows the family relationships (Fig. 1).

Physical examination of the patient revealed the following characteristic signs of Down's syndrome: bilateral epicanthal folds; bilateral simian lines; Brushfield spots bilaterally; brachycephaly; a high arched palate; a short neck; a small umbilical hernia; wide space between the great and second toes; dermatoglyphs which showed 10 ulnar loops on the fingers, with a normal axial palmar triradius on the right hand and a $t^{\prime}$ on the left hand. The external genitalia were normal male and both testes were descended. The heart examination showed a systolic murmur which was associated with increased vascularity in the lung fields on $x$-ray and a normal electrocardiogram. Subsequent evaluation of the heart suggested a ventricular septal defect or an endocardial cushion defect with probable pulmonary

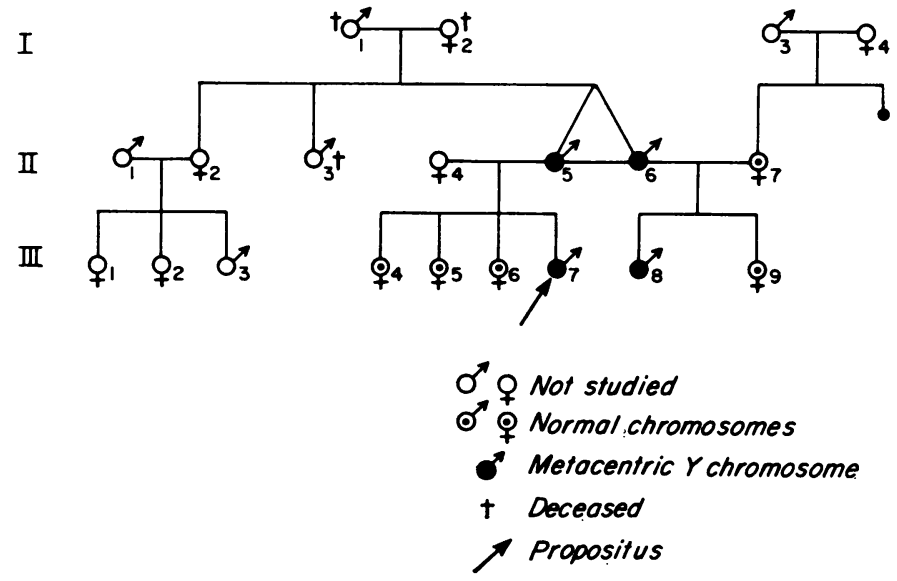

FIG. 1. Pedigree of the family. Note that all examined male family members have the metacentric $\mathrm{Y}$ chromosome. 
TABLE

RESULTS OF BLOOD CHROMOSOME ANALYSES IN ALL FAMILY MEMBERS

\begin{tabular}{|c|c|c|c|c|c|c|c|c|}
\hline \multirow{2}{*}{ Person* } & \multirow{2}{*}{ Relationship } & \multicolumn{3}{|c|}{$\begin{array}{c}\text { Chromosome } \\
\text { Counts }\end{array}$} & \multirow{2}{*}{$\begin{array}{c}\text { Total } \\
\text { Cells } \\
\text { Counted }\end{array}$} & \multicolumn{3}{|c|}{ Karyotypes } \\
\hline & & 45 & 46 & 47 & & Regular & $\underset{\text { radiograph }}{\text { Auto- }}$ & Interpretation \\
\hline $\begin{array}{r}\text { III. } 8 \\
\text { III. } \\
\text { III.6 } \\
\text { III.7 } \\
\text { III.9 } \\
\text { III.5 } \\
\text { IIII.7 } \\
\text { III.4 } \\
\text { III.5 } \\
\text { III.6 }\end{array}$ & $\begin{array}{l}\text { Propositus } \\
\text { Propositus (skin) } \\
\text { Father } \\
\text { Mother } \\
\text { Sister } \\
\text { Paternal uncle } \\
\text { Paternal cousin } \\
\text { Paternal cousin } \\
\text { Paternal cousin } \\
\text { Paternal cousin }\end{array}$ & $\begin{array}{l}1 \\
3 \\
2 \\
3 \\
2 \\
1 \\
2\end{array}$ & $\begin{array}{r}9 \\
78 \\
25 \\
22 \\
26 \\
64 \\
24 \\
25 \\
28\end{array}$ & $\begin{array}{r}112 \\
20\end{array}$ & $\begin{array}{r}122 \\
20 \\
81 \\
27 \\
25 \\
28 \\
64 \\
25 \\
25 \\
30\end{array}$ & $\begin{array}{l}\mathbf{5} \\
\mathbf{5} \\
\mathbf{5} \\
\mathbf{5} \\
\mathbf{5} \\
\mathbf{5} \\
\mathbf{5} \\
\mathbf{5} \\
\mathbf{5} \\
\mathbf{5}\end{array}$ & $\begin{array}{l}5 \\
5 \\
5 \\
5\end{array}$ & $\begin{array}{l}\text { 47,Xinv }(Y p+q-), 21+ \\
\text { 47,Xinv }(Y p+q-), 21+ \\
\text { 46,Xinv }(Y p+q-) \\
\text { 46,XX } \\
\text { 46,XX } \\
\text { 46,Xinv }(Y p+q-) \\
\text { 46,Xinv }(Y p+q-) \\
\text { 46,XX } \\
\text { 46,XX } \\
\text { 46,XX }\end{array}$ \\
\hline
\end{tabular}

* See pedigree (Fig. 1).

hypertension and an increasing heart size. Routine urine and blood examination were within normal limits.

Chromosome studies. Routine blood chromosome studies were performed according to the method of Arakaki and Sparkes (1963). Autoradiographic studies used the method of Schmid (1963). Skin fibroblast cultures were established according to the method of Harnden (1960).

\section{Results}

The results of the chromosome analyses and their interpretations are summarized in the Table. A full regular and autoradiographic karyotype on the propositus shows trisomy 21 plus the inversion in the late labelling $\mathrm{Y}$ chromosome (Fig. 2). In Fig. 3

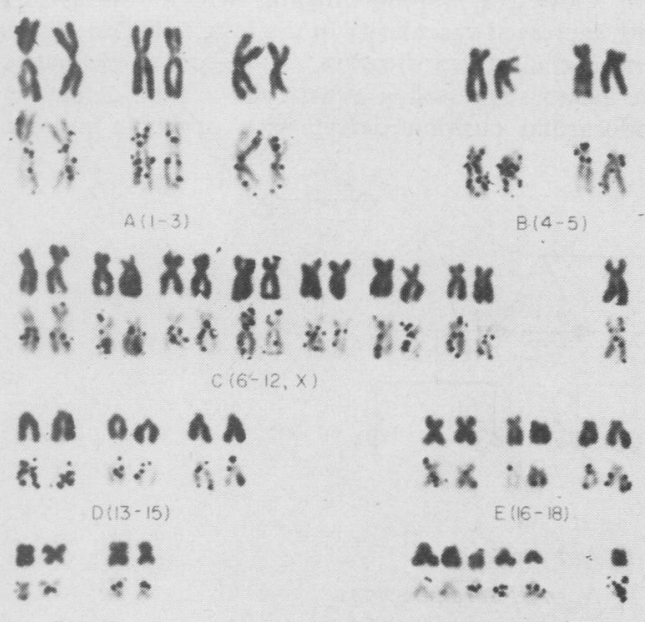

Fig. 2. Karyotype prepared from blood cell of propositus (III.8). Below each chromosome is its autoradiographic labelling pattern. The presumed pericentric inversion $Y$ chromosome is late labelling. Examination of the $G$ group chromosomes suggests trisomy of the late labelling pair. are seen partial karyotypes (F, G, and Y chromosomes) from the four male family members. The similar appearance of the inverted $\mathrm{Y}$ chromosome to an $\mathrm{F}$ group chromosome can be seen. The results of the chromosome studies are interpreted as showing a pericentric inversion of the $\mathrm{Y}$ chromosome in all male members of the family plus a regular trisomy 21 in the propositus. Buccal sex chromatin in the propositus and his father show a normal pattern.

\section{Discussion}

Cytogenetic studies in the present family indicate a pericentric inversion of the $\mathrm{Y}$ chromosome which is found in all four male family members who were studied. The reasons for interpreting the abnormal chromosome as a $\mathrm{Y}$ are that it is found only in males; the size of the chromosome is compatible with its derivation from a $\mathrm{Y}$ chromosome; it shows a late labelling pattern on autoradiography with tritiated thymidine, as is found with normal $\mathrm{Y}$ chromosomes; and there is no normal $\mathrm{Y}$ chromosome seen. It is thought to be a pericentric inversion because it has no obvious phenotypic effect, its size is similar to a normal Y chromosome, and only one chromosome in the complement appears to be affected, which is against a translocation. Conclusive determination that it represents a pericentric inversion of a $\mathrm{Y}$ chromosome is limited by the absence of males from earlier generations who might have a normal $Y$ chromosome, and because the chromosome is too small to use a specific autoradiographic labelling pattern to distinguish between an inversion and other possibilities.

Since the $\mathrm{X}$ and $\mathrm{Y}$ chromosome pair end to end rather than side to side, a search for meiotic inversion loops would probably not be fruitful. Meiotic study in one patient who was considered to have a pericentric inversion of the $\mathrm{Y}$ chromosome did not 


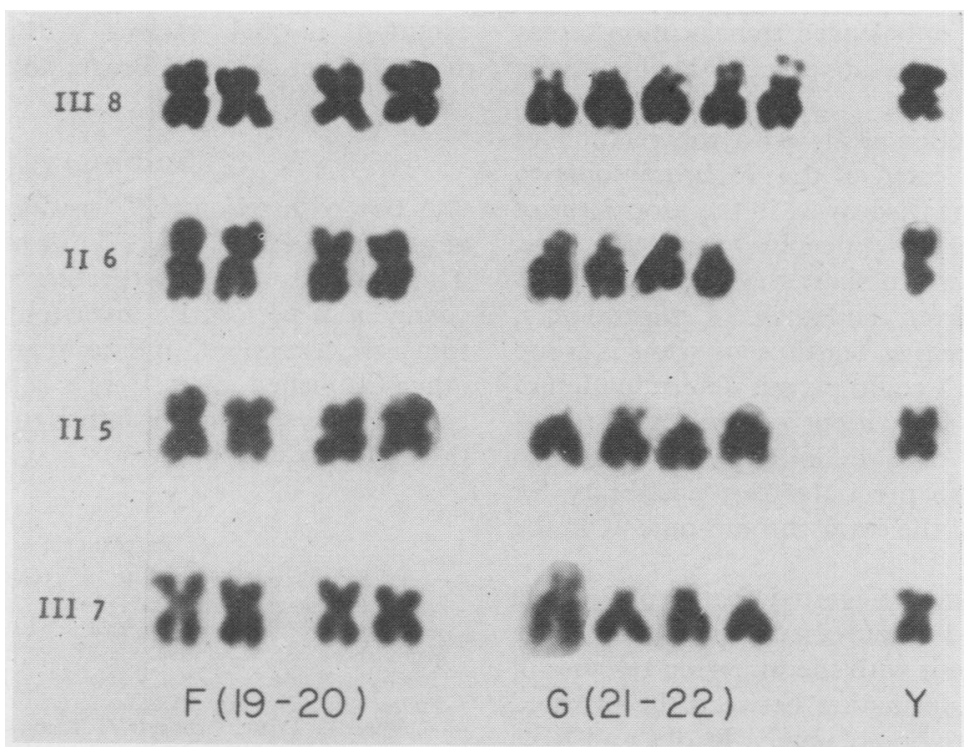

Fig. 3. Partial karyotypes of the F, G, and $Y$ chromosomes from each male family member show the metacentric appearance of the $Y$ chromosome which tends to be slightly smaller than the $\mathrm{F}$ group chromosomes. To the left of each partial karyotype is the pedigree identification of the person from whom it was prepared.

reveal any abnormality in pairing between the $\mathrm{X}$ and Y chromosomes (McIlree et al., 1966).

The present findings are similar to other cases of presumed pericentric inversions of a $\mathrm{Y}$ chromosome. One patient was a 73-year-old man who had no children, was $152 \mathrm{~cm}$. tall, and had a harelip (Court Brown, Jacobs, and Brunton, 1965; Court Brown et al., 1966; Jacobs, Brunton, and Court Brown, 1964; Jacobs and Ross, 1966). An isochromosome of the Y chromosome was considered unlikely because of the normal male phenotype. A second patient (Case 4 in Jacobs and Ross, 1966) is a 41year-old man with features of the Klinefelter syndrome. Chromosome studies showed 47 chromosomes with two $\mathrm{X}$ chromosomes and positive sex chromatin findings, as well as a metacentric $Y$ chromosome. A male pseudohermaphrodite with a complex chromosome picture including mosaicism involving the sex chromosomes was considered by the authors to have an isochromosome of the Y chromosome, but by appearance it could represent a pericentric inversion (Klevit, Mellman, and Eberlein, 1963). Another apparently normal man with oligospermia was found to be $45, \mathrm{X} / 46, \mathrm{XY}$, with a metacentric Y chromosome (McIlree et al., 1966). Pfeiffer and Pawlovitzki (1967) suggested that a male with the Turner phenotype and a $45, \mathrm{X} / 47, \mathrm{XY}$ plus a submetacentric chromosome had a pericentric inversion of the $\mathrm{Y}$ chromosome. Solomon, Hamm, and Green (1964) studied an 11-year-old boy with mental retardation and internal testes. We agree with the suggestion of Jacobs and Ross (1966) that this patient most probably has a pericentric inversion of the $\mathrm{Y}$ chromosome. Another patient was thought to have a probable isochromosome of the Y chromosome (Stoeckenius, 1966), but its appearance suggests a pericentric inversion. This family situation is similar to our family in that the patient has a mongol daughter, and both he and his father have the metacentric $\mathrm{Y}$ chromosome.

Other possible interpretations of the chromosome findings in the present family seem less likely. An isochromosome of the $\mathrm{Y}$ seems ruled out by the fact that it is too large to be an isochromosome of the short arms of a Y chromosome, while it is probably too short for an isochromosome of the long arms; in addition, the chromosome is not exactly metacentric as would be expected in an isochromosome; and, further, in two reports (Court Brown et al., 1964; Jacobs and Ross, 1966) isochromosomes of the Y have been associated with phenotypic sexual abnormalities. A balanced translocation between a Y chromosome and some other chromosome cannot be ruled out. However, the chance that all four persons would have this translocated chromosome in a balanced state seems unlikely, though it is possible that only balanced children of the carriers would survive. There is no obvious evidence of a translocation in the chromosome complement in the affected persons but its small size could lead to its 
being missed. An unbalanced translocation seems unlikely because of the absence of a phenotypic effect.

A final consideration deals with the relation of this pericentric inversion of the $\mathrm{Y}$ chromosome to the occurrence of the trisomy 21 in the propositus of our family. If there is a meaningful relation here, it would be necessary to show that the extra chromosome has come from the father. Unfortunately, there are no distinctive features of the $G$ group chromosomes, which could permit determination of parental origin of the patient's G group chromosomes. The lack of a definite gene marker on chromosome 21 also precludes this possibility for tracing the origin of the extra chromosome 21 in the patient.

Some authors have suggested that a pericentric inversion could lead to increased non-disjunction in children of the parent with the inversion because of reduced chiasmata formation between the inverted chromosome and its homologue. Jacobs and Ross (1966) discuss this possibility in their Case 4, and interpret the findings of Solomon et al. (1964) as also suggestive of the pericentric inversion increasing the chance for non-disjunction of the $\mathrm{X}$ and $\mathrm{Y}$ chromosomes in their families. If one accepts the interpretation that the change in the $\mathrm{Y}$ chromosome in the family of Stoeckenius (1966) represents a pericentric inversion, then our family represents a second instance in which a parent with an inverted $Y$ has had a trisomic Down's syndrome child. Schmid (1967) and Soudek, Laxová, and Adámek (1968) also suggest that inversion heterozygosity could increase the risk of having aneuploid offspring.

The small number of persons who have been detected with a pericentric inversion of the $Y$ chromosome makes it difficult to reach a definite conclusion as to the possible increased risk of a person with this chromosome for having a child with an aneuploid complement. Most of the persons reported have been ascertained through some phenotypic abnormality either in themselves or in their relatives. This ascertainment bias is also clear in the present family which was initially detected through the child with Down's syndrome. The finding of two persons with a presumed pericentric inversion of a Y chromosome in a survey of 2400 normal newborn infants suggests that this may be a relatively common normal variant without a consistent meiotic effect (Walzer, Breau, and Gerald, 1969).

\section{Summary}

A boy with trisomy 21 was found to have an inherited pericentric inversion of his $\mathrm{Y}$ chromosome. The reasons for interpreting the chromosome change as a pericentric inversion of the $\mathrm{Y}$ chromosome are presented, and comparison is made with other published cases. The relation of the pericentric inversion in the father to the trisomy 21 in the child is discussed.

\section{REFERENCES}

Arakaki, D. T., and Sparkes, R. S. (1963). Microtechnique for culturing leukocytes from whole blood. Cytogenetics, 2, 57-60.

Court Brown, W. M., Buckton, K. E., Jacobs, P. A., Tough, I. M., 0 Kuenssberg, E. V., and Knox, J. D. E. (1966). Chromosome Studies on Adults. Eugenics Laboratory Memoirs, Vol. 42. Cambridge University Press, London.

- Harnden, D. G., Jacobs, P. A., Maclean, N., and Mantle, D. J. (1964). Abnormalities of the sex chromosome complement in man. Medical Research Council Special Report Series, No. 305. - Jacobs, P. A., and Brunton, M. (1965). Chromosome studies on randomly chosen men and women. Lancet, 2, 561-562.

Harnden, D. G. (1960). A human skin culture technique used for cytological examination. British fournal of Experimental Patho$\log y, 41,31-37$.

Jacobs, P. A., Brunton, M., and Court Brown, W. M. (1964). Cytogenetic studies in leucocytes on the general population. Subjects of ages 65 years and more. Annals of Human Genetics, 27, 353-362.

, and Ross, A. (1966). Structural abnormalities of the Y chromosome in man. Nature (London), 210, 352-354.

Klevit, M. D., Mellman, W. J., and Eberlein, W. R. (1963). Triple mosaicism with an isochromosome derived from a partially deleted $\mathrm{Y}$ in a male pseudohermaphrodite. Pediatrics, 32, 56-62.

McIlree, M. E., Price, W. H., Court Brown, W. M., Tulloch, W. S. Newsam, J. E., and Maclean, N. (1966). Chromosome studies on testicular cells from 50 subfertile men. Lancet, 69-71.

Pfeiffer, R. A., and Pawlovitzki, J. H. (1967). Turner's syndrome in the male with chromosomal mosaicism. Humangenetik, 4, 136139.

Schmid, W. (1963). DNA replication patterns of human chromosomes. Cytogenetics, 2, 175-193.

- (1967). Pericentric inversions. Report on two malformation cases suggestive of paternal inversion heterozygosity. Fournal de Génétique Humaine, 16, 89-96.

Solomon, I. L., Hamm, C. W., and Green, O. C. (1964). Chromosome studies on testicular tissue cultures and blood leukocytes of a male previously reported to have no Y chromosome. New England fournal of Medicine, 271, 586-592.

Soudek, D., Laxová, R., and Adámek, R. (1968). Pericentric inversion in a family with a $21 / 22$ translocation. Cytogenetics, 7, 108-117.

Stoeckenius, M. (1966). A probable $Y$ isochromosome in father and son of tall stature. Lancet, $2,391$.

Walzer, S., Breau, G., and Gerald, P. S. (1969). A chromosome survey of 2,400 normal newborn infants. Fournal of Pediatrics, 74 438-448. 